\title{
Maternal cured meat consumption during pregnancy and risk of paediatric brain tumour in offspring: potentially harmful levels of intake
}

\author{
Janice M Pogoda ${ }^{1, *}$ and Susan Preston-Martin ${ }^{2}$ \\ ${ }^{1}$ Statology, 10355 Pine Cone Way, Truckee, CA 96161, USA: ${ }^{2}$ University of Southern California (USC), \\ Department of Preventive Medicine, USC/Norris Comprehensive Cancer Center, Los Angeles, CA 90033-0800, \\ USA
}

\begin{abstract}
Objective: To describe the relationship between specific levels of nitrite intake from cured meat consumption during pregnancy and the relative risk of paediatric brain tumours in the offspring.

Design: Exposure data were previously collected for a population-based casecontrol study of paediatric brain tumours; data on nitrite content were obtained by a comprehensive literature review of surveys of residual nitrite content in cured meats published in the USA and Canada. The level of nitrite intake for each mother was predicted by year of pregnancy based on survey results. Dose-response was evaluated both categorically and continuously using polynomial and quadratic spline regression.

Setting: The US west coast: Los Angeles County, the San Francisco-Oakland Bay Area and the Seattle-Puget Sound area.

Subjects: There were 540 cases diagnosed between 1984 and 1990 at ages varying from 0 to 19 years, and 801 controls frequency-matched by geographic area, age and birth year.

Results: In general, survey results suggest a trend of decreasing nitrite levels in cured meats over time. We observed a moderate increase in brain tumour risk in the offspring of mothers with relatively low levels of nitrite consumption from cured meats during pregnancy, and a two- to three-fold risk increase in offspring of mothers who consumed $3 \mathrm{mg}$ day $^{-1}$ nitrite from cured meats (about $125 \mathrm{~g} \mathrm{day}^{-1}$ of cured meat consumption throughout the pregnancy).

Conclusions: A substantial risk of paediatric brain tumour appears to be associated with relatively high levels of maternal cured meat consumption during pregnancy. A more scientifically valid approach than a literature review to estimate nitrite intake from cured meats and data from a large group of highly exposed subjects would be useful in determining potentially harmful levels.
\end{abstract}

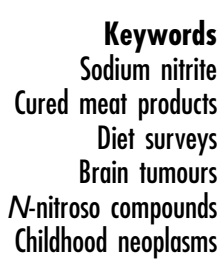

It has been suggested that $N$-nitroso compounds (NOC) formed by in vivo reaction, mainly in the stomach, between nitrites and secondary or tertiary amines or amides may be a major contributor to human cancer risk ${ }^{1}$ and that half of all human NOC exposure is from endogenous formation ${ }^{2}$. Cured meats may be the most important source of human NOC exposure because of the high level of reactivity produced by high concentrations of nitrite that form around bits of cured meat in the stomach ${ }^{3}$. One group of NOC, the nitrosoureas, causes neurogenic tumours of various histological types in several species ${ }^{4,5}$ and is most effective when exposure is transplacental ${ }^{6}$. In monkeys, the histological distribution of tumours produced by transplacental exposure to ethylnitrosourea (ENU) is similar to the histological distribution of human paediatric brain tumours, which are mostly glial (i.e. various types of gliomas, such as astrocytomas), and no tumours are produced by postnatal exposure ${ }^{7}$.

We previously reported a significant dose-response association between paediatric brain tumour risk and maternal consumption of cured meats during pregnancy in a large, population-based case-control study ${ }^{3}$. The odds ratio (OR), an estimate of relative risk in retrospective studies, was significantly elevated for the highest quartile of exposure (based on the distribution of exposure among all subjects) which corresponded to an 
average nitrite consumption from cured meats greater than $1.28 \mathrm{mg} \mathrm{day}^{-1}$. Nitrite levels for individual types of cured meats were based on dietary conversion software provided by Dr Geoffrey Howe (Columbia University School of Public Health, New York) and used published nitrite contents for the cured meats in our study.

Since publishing our initial findings, we have attempted to determine a more valid level of exposure at which relative risk becomes significantly elevated. Because of the widely publicized health concerns associated with NOC, it is reasonable to expect that, over time, meat manufacturers have independently reduced nitrite levels in their products through thermal processing, adding reducing agents such as ascorbate, lowering $\mathrm{pH}$ levels, and using higher storage temperatures and longer storage times ${ }^{8-10}$. Thus, a single estimate of nitrite content may not be appropriate in a study such as ours with an exposure period that spanned three decades. We therefore conducted our own literature search and developed a database of published nitrite levels by year of publication. We then determined predicted nitrite levels for each type of cured meat based on year of publication and used these predicted levels to assign nitrite exposure to our study subjects based on year of pregnancy. We reanalysed our data using these new exposure levels and chose fixed cut-off points for categorical analysis rather than basing the cut-off points on the distribution of exposure. Finally, we related nitrite exposure levels to units of cured meat consumption to express potentially harmful consumption levels in a more intuitive manner.

\section{Methods}

The US West Coast Childhood Brain Tumour Study has been described in detail elsewhere ${ }^{3}$. Briefly, the study included 540 cases and 801 controls, aged 0-19 years, from 19 counties in three West Coast regions: Los Angeles County, 13 counties in western Washington state, including the Seattle-Puget Sound area, and five counties in the San Francisco-Oakland metropolitan area. Cases were diagnosed from January 1984 to December 1990 (Seattle, San Francisco) or through June 1991 (Los Angeles). Controls were recruited from the same three geographic areas using random digit dialing ${ }^{11}$ and frequencymatched to cases by area, gender and birth year.

Reference ages were assigned based on diagnosis ages of cases within each stratum defined by the matching variables. As part of a larger interview that primarily emphasized prenatal and childhood exposure to NOC, mothers were asked about their intake of 47 food items relevant to the NOC hypothesis during the past year and during their pregnancies. Data on the frequency of consumption and portion sizes (measured using abstract food models) were converted to average daily grams of consumption using a dietary conversion software program provided by Dr Geoffrey Howe of Columbia University $^{12}$.

Several sources were used to gather all surveys of NOC or NOC precursor content in commercially available cured meats published in the USA or Canada since 1965. Initially, Medline was searched using keywords 'nitrite', 'nitrate', ' $N$-nitroso compounds', and 'cured meat' to find relevant literature, most of which was published in food science journals. From the articles retrieved, relevant articles in older journals and journals not covered by Medline were found. We also searched Food and Drug Administration publications available on microfiche and contacted various institutions (US Department of Agriculture Food Safety and Inspection Division, American Meat Institute, National Livestock and Meat Board, Dr Walter Fiddler at the Agricultural Research Service) to determine if any other survey data had been published and to obtain available documentation. Results from studies that altered the product, e.g. NOC added to test measurement methods, were excluded.

A total of 85 surveys were reviewed; 26 of these reported sodium nitrite (hereafter referred to as nitrite) levels using several different testing methods: spectrophotometric $^{8}$, colorimetric ${ }^{13-16}$, diazotization ${ }^{17}$, the Griess-Saltzman method ${ }^{18-23}$ and methods recommended by the Association of Official Analytical Chemists $^{24-27}$. Methods were not specifically stated for 10 surveys contained in six references ${ }^{9,28-32}$. In tabulating survey results, we classified meats into five categories that corresponded to those used in our case-control study interview: bacon (fried and raw); sausage; hot dogs; ham; and other cured meats, which included lunch meats, meat loaves and pork. Hot dog varieties used in the surveys included beef, chicken, pork, fish and cheese. Approximately 30 varieties of sausage were surveyed, the most common being Vienna, salami, mettwurst, summer, Lebanon bologna, liver, pepperoni, Polish and knockwurst. Ham preparation methods included raw, canned, smoked, cooked and fried. Curing methods used were dry, immersion and pumped.

Original data published in the surveys, if available, were used for analysis. Nineteen references provided original data, three provided only summary data (averages and/or ranges) and four provided a combination of original and summary data. When only summary data were available, average nitrite levels weighted by sample sizes were used. Polynomial regressions (SAS/ STAT Version 6.04, SAS Institute, Cary, NC) of residual nitrite level on survey publication year, weighted by the number of meat samples surveyed and excluding obvious outliers, were performed to determine the best-fitting model and to compute residual nitrite (in $\mathrm{mg} \mathrm{kg}^{-1}$ ) predicted by publication year for each category of cured meat. 'Publication year' was defined as the year the survey was published, even if the survey was cited in a subsequently published article; e.g. if a survey was 
Table 1 Median and midspread (25th-75th percentiles) residual nitrite levels ( $\mathrm{ppm}$ ) in cured meats according to published surveys by year of publication and category of cured meat

\begin{tabular}{|c|c|c|c|c|c|c|c|c|c|c|c|c|}
\hline \multirow[b]{2}{*}{ Cured meat category } & \multicolumn{3}{|c|}{$1970-1975$} & \multicolumn{3}{|c|}{$1976-1980$} & \multicolumn{3}{|c|}{$1981-1985$} & \multicolumn{3}{|c|}{$1986-1991$} \\
\hline & $n^{\star}$ & Median & Midspread & $n$ & Median & Midspread & $n$ & Median & Midspread & $n$ & Median & Midspread \\
\hline All combined & 408 & 14 & $(7-39)$ & 518 & 34 & $(15-58)$ & 110 & 14 & $(8-38)$ & 66 & 30 & $(18-47)$ \\
\hline Bacon† & 85 & 25 & $(12-51)$ & 310 & 40 & $(22-63)$ & 47 & 28 & $(14-45)$ & 49 & 27 & $(14-40)$ \\
\hline Sausage & 98 & & - & 36 & 13 & $(3-25)$ & 24 & 8 & $(6-12)$ & 0 & & - \\
\hline Hot dogs $\S$ & 33 & 14 & $(7-21)$ & 30 & 35 & $(18-51)$ & 13 & 22 & $(13-42)$ & 17 & 47 & $(28-65)$ \\
\hline Ham" & 44 & 18 & $(7-54)$ & 83 & 16 & $(6-62)$ & 11 & 8 & $(3-52)$ & 0 & & - \\
\hline Other cured meats" & 148 & 10 & $(4-40)$ & 59 & 28 & $(14-43)$ & 15 & 9 & $(5-14)$ & 0 & 12 & $(10-20)$ \\
\hline
\end{tabular}

* Number of meat samples surveyed.

† References 9, 13-20, 23, 26-29, 31.

† References $8,13,14,20,25,26,28$.

§ References 8, 13, 14, 20-22, 24-26, 28.

II References 13, 14, 20, 25, 26, 28, 31 .

If References 8, 13, 14, 20, 25, 26, 28, 30, 31.

originally published in 1970 but was cited in an article published in 1975, 'publication year' for data from that survey was 1970. Log-transformed data better satisfied the homoscedasticity and normality regression assumptions than non-transformed data.

For each category of cured meat, average daily nitrite intake during pregnancy was calculated using average daily consumption of each category and nitrite intake per kilogram of consumption (i) predicted by pregnancy year plus one (to account for publication lag time) using the derived regression equations described above, and (ii) based on the Howe dietary conversion software. Total nitrite intake from cured meats was derived by summing nitrite intake over all cured meat categories. Unconditional logistic regression (Epilog Plus Version 3.99,
Epicenter Software, Pasadena, CA) stratified by geographic area, gender, diagnosis (or reference) age and birth year was used to compute maximum likelihood estimates of ORs and $95 \%$ confidence intervals for relating maternal nitrite intake from cured meats to risk of paediatric brain tumour. Race and socioeconomic status (SES) were evaluated as potential confounders and effect modifiers. Both variables, however, had little effect on OR estimates when included as possible confounders, and OR estimates did not differ substantially by race or level of SES. Therefore, we present results that are unadjusted for and unstratified by race and/or SES. Cut-off points for categorical analysis were set a priori at 0, 0.5, 1, 2 and $3 \mathrm{mg}$. Using these same values as knots, quadratic spline regression with linear restriction of the upper tail was

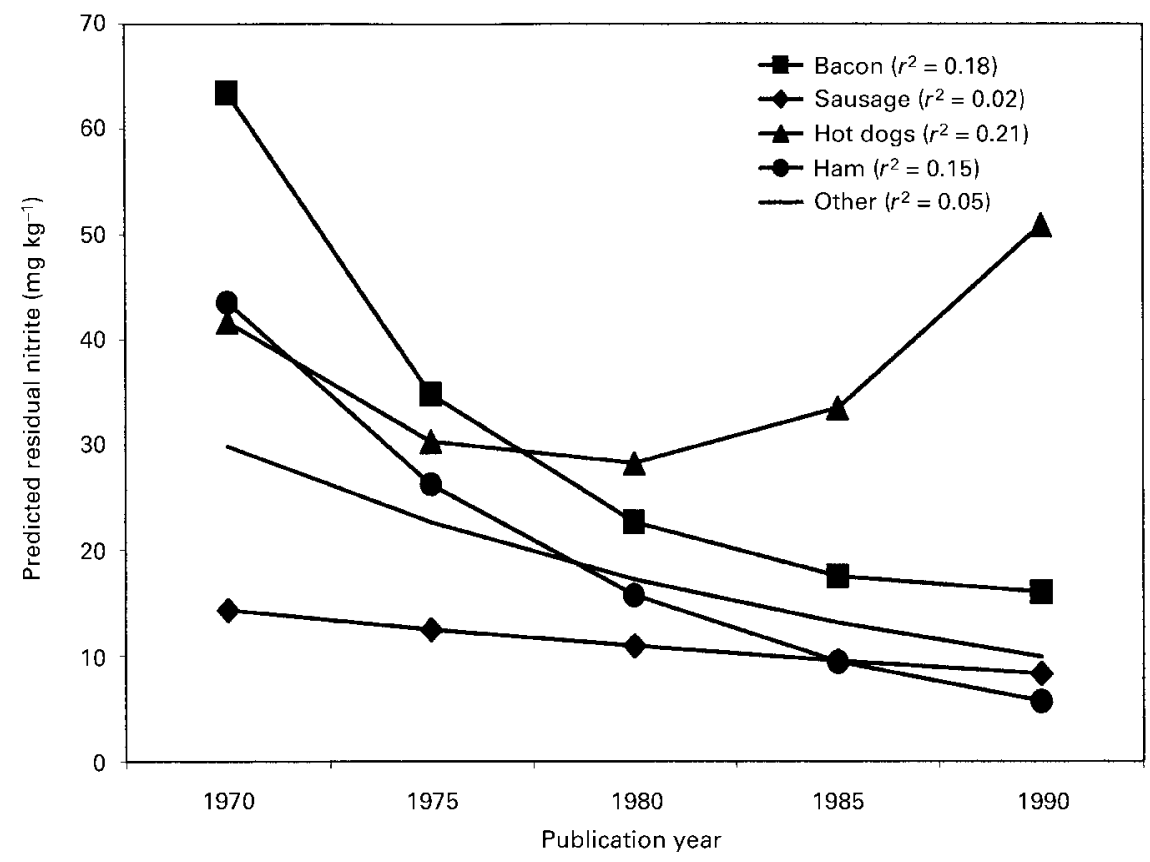

Fig. 1 Residual nitrite levels in cured meats predicted by publication year of survey literature, 1970-1991. Each point represents predicted $\mathrm{mg}$ nitrite $/ \mathrm{kg}$ cured meat product for a given year. Trends were significant for bacon ( $P=0.001$ for linear term, 0.003 for quadratic), ham $(P=0.0001)$, other cured meats $(P=0.001)$ and hot dogs $(P=0.007$ for linear term, 0.005 for quadratic) 


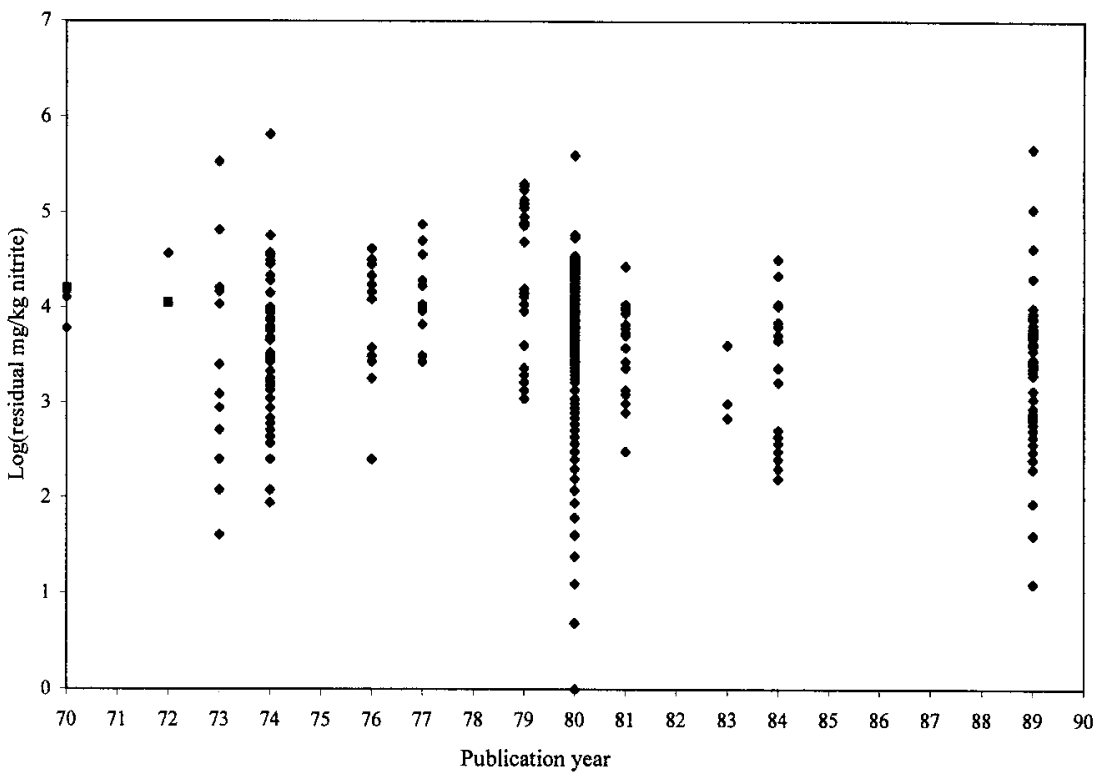

Fig. 2 Log(residual nitrite) in bacon by publication year of survey. Each point represents log(reported mg nitrite/kg bacon) from a single survey. Linear and quadratic terms in test for trend were significant $(P=0.001$ for linear, 0.003 for quadratic)

used to fit a smooth curve over the range of literaturebased nitrite exposure ${ }^{33}$. The spline model was compared to a model containing only the linear component of exposure by the likelihood ratio test. All tests were twosided with a 0.05 significance level.

\section{Results}

Within our target time period of 1965 to 1991 (the birth year range of our study subjects), no published nitrite surveys were available prior to 1970 , nor were all years in the time period represented. Within samples defined by meat and year, sample sizes ranged from one to 260. In this context, 'sample size' refers to the number of meat samples summed over all surveys performed on a given type of meat in a given year. Residual ranges (in ppm) were very wide, particularly for bacon (Table 1 ). There were two outlying values of residual ppm for bacon and three for hot dogs that were omitted from regression analyses to predict nitrite exposure by year. As shown in
Fig. 1, there were decreasing trends in predicted nitrite levels by survey publication year for bacon (regression coefficient for linear term $[\beta]$ for $\log (\mathrm{ppm})=-0.61$, standard error $[\mathrm{SE}]=0.19, P=0.001$; for quadratic term $\left.\left[\beta^{2}\right]=0.003, \mathrm{SE}=0.001, P=0.004\right)$, ham $(\beta=-0.10$ $\mathrm{SE}=0.021, P=0.0001)$, sausage $(\beta=-0.03, \mathrm{SE}=0.016$, $P=0.09)$ and 'other cured meats' $(\beta=-0.05, \mathrm{SE}=$ $0.017, P=0.001)$ and, after 1980, an increasing trend for hot dogs $\left(\beta=-0.77\right.$, SE $=0.28, P=0.007 ; \beta^{2}=$ $0.005, \mathrm{SE}=0.002, P=0.005)$. Percentages of variation accounted for by the regressions $\left(r^{2}\right)$ are reported in the figure. Despite the significant regression coefficients for all cured meats but sausage, the low $r^{2}$ values indicate that very little of the variability in nitrite levels reported in the surveys is explained by publication year. This is illustrated for bacon in Fig. 2.

Categorical dose-response relating average daily nitrite (in mg) consumption from cured meats to paediatric brain tumour risk is shown in Table 2. With estimated nitrite intake based on our literature review, there is an

Table 2 Comparison of odds ratios (OR) and 95\% confidence intervals $(\mathrm{Cl})$ at fixed categories of maternal nitrite exposure from consumption of cured meats during pregnancy by source of nitrite estimation, US West Coast Childhood Brain Tumour case-control study, 1984-1991

\begin{tabular}{|c|c|c|c|c|c|c|}
\hline \multirow{2}{*}{$\begin{array}{l}\text { Average daily nitrite } \\
\text { from cured meats (mg) }\end{array}$} & \multicolumn{3}{|c|}{ Time-specific nitrite estimates from literature review } & \multicolumn{3}{|c|}{ Nitrite estimates from dietary conversion software } \\
\hline & No. of cases (\%) & No. of controls (\%) & OR $(95 \% \mathrm{Cl})$ & No. of cases (\%) & No. of controls (\%) & OR $(95 \% \mathrm{Cl})$ \\
\hline$\overline{0}$ & $102(20)$ & $161(20)$ & 1.0 & $102(20)$ & $161(20)$ & 1.0 \\
\hline $0.01-0.49$ & $293(57)$ & 499 (63) & $1.1(0.8,1.5)$ & 377 (73) & $601(75)$ & $1.2(0.9,1.6)$ \\
\hline $0.50-0.99$ & $68(13)$ & 72 (9) & $1.9(1.2,2.9)$ & $27(5)$ & $24(3)$ & $2.3(1.3,4.4)$ \\
\hline $1.00-1.99$ & $28(5)$ & $43(5)$ & $1.3(0.8,2.3)$ & $6(1)$ & $10(1)$ & $1.3(0.5,3.3)^{*}$ \\
\hline $2.00-2.99$ & $12(2)$ & $13(2)$ & $1.8(0.8,4.1)$ & $2(0.4)$ & $0(0)$ & - \\
\hline$\geq 3.0$ & $11(2)$ & $9(1)$ & $3.0(1.2,7.9)$ & $0(0)$ & $1(0.1)$ & - \\
\hline
\end{tabular}

* Includes two cases and one control with exposure $\geq 2 \mathrm{mg} \mathrm{day}^{-1}$. 


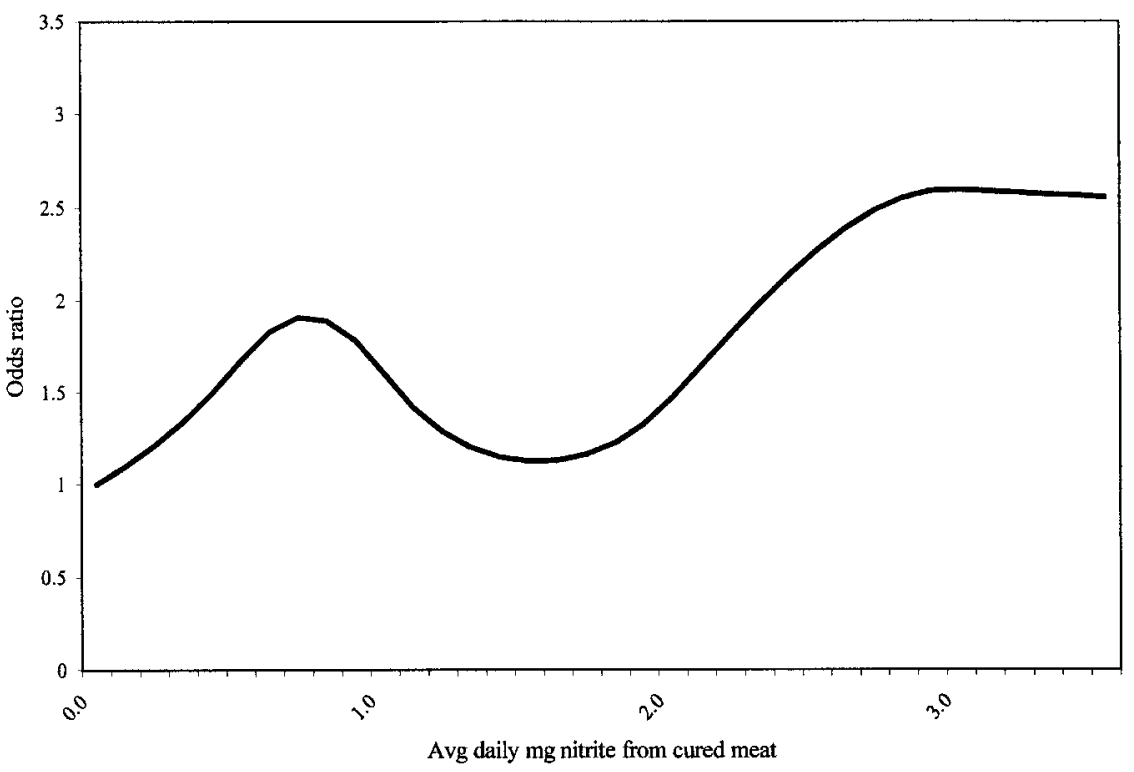

Fig. 3 Fitted odds ratio of paediatric brain tumour associated with maternal intake of nitrite (average mg day ${ }^{-1}$ ) from cured meats during pregnancy with time-specific predicted nitrite levels based on the literature review. Restricted quadratic spline with knots at $0.5,1,2$ and 3

indication of increasing OR with increasing exposure and significantly increased OR at exposure levels of at least $3 \mathrm{mg} \mathrm{day}^{-1}$. Among subjects with nitrite intake levels of at least $3 \mathrm{mg} \mathrm{day}^{-1}$, median cured meat consumption was $124 \mathrm{~g} \mathrm{day}^{-1}$. This roughly corresponds to three hot dogs (1 hot $\operatorname{dog}=45 \mathrm{~g}$ ), 20 slices of bacon (1 slice cooked bacon $=6.3 \mathrm{~g})$, five pork sausage links $(1$ link $=24 \mathrm{~g})$, over four slices of lunch meat $(1$ slice $=28.35 \mathrm{~g})$ or one cup of diced ham $(1 \text { cup }=135 \mathrm{~g})^{34}$. With estimated nitrite based on the dietary conversion software, categorical dose-response using the same exposure cut-off points could not be adequately evaluated because very few mothers were in the highest categories of exposure. At intermediate exposure levels (0.5-0.99 $\mathrm{mg} \mathrm{day}^{-1}$ ), the OR was somewhat higher using the dietary conversion software than using the time-specific literature-based estimates of nitrite intake (OR $=2.3$ vs 1.9$)$.

The linear trend relating literature-based average daily mg nitrite consumption from cured meats (as a continuous variable) to relative risk of paediatric brain tumour was highly significant $(\beta(\mathrm{SE})=0.22(0.08) ; P=0.008)$. Although quadratic spline regression did not significantly improve the fit to the data $(P=0.09)$, the dose-response curve suggests a moderate (maximum $\mathrm{OR}=1.9$ ) increase in paediatric brain tumour OR at low levels of maternal nitrite exposure (up to $1 \mathrm{mg} \mathrm{day}^{-1}$ ) followed by another OR increase beginning at about $1.5 \mathrm{mg} \mathrm{day}^{-1}$ with an OR of 2.5 at $3 \mathrm{mg} \mathrm{day}^{-1}$ (Fig. 3).

Evaluation of time as an effect modifier would have been useful to confirm an association between higher nitrite exposure and increased risk. However, this was not possible due to the relationships among age, birth era and effects of prenatal risk factors. One of the case inclusion requirements in our study population was diagnosis no earlier than 1984. Thus, subjects born in the earliest years were the oldest subjects and all of the youngest subjects were born no earlier than 1980. Since prenatal risk factors would be expected to act early in life, increased risk from nitrite among the earliest birth year subjects is likely to be obscured by the fact that these were also the oldest subjects.

\section{Discussion}

Other studies besides ours have reported elevated risk related to maternal cured meat consumption; however, all of them had limitations that prevented valid quantification of potentially harmful levels of nitrite and/or cured meat intake: significant increasing dose-response was demonstrated but amounts of consumption were not reported ${ }^{35}$, dose-response analysis was not reported $^{36}$, clear evidence of dose-response was not present ${ }^{37}$, or doseresponse was restricted to low-income subjects only ${ }^{38}$. Because of the high prevalence of exposure to cured meats $-80 \%$ of all mothers in our study ate some cured meat while pregnant - we felt it was important to try to determine a level of nitrite and corresponding cured meat consumption at which risk of paediatric brain tumour became significantly increased. In doing so, we found it necessary to consider chronological trends by type of cured meat. Our study subjects were born between 1965 and 1991, a particularly active period in governmental and consumer interest in nitrite in cured meats ${ }^{2}$. The surveys we reviewed suggest that meat manufacturers responded by significantly reducing nitrite levels in all products except hot dogs, in which nitrite levels seem to have increased after 1980 (Fig. 1).

Literature review may be the only method available to 
obtain data such as human nitrite intake from cured meats; however, this approach does have a serious scientific limitation in that the surveys are not controlled so that they are consistent and directly comparable to each other. For example, residual nitrite levels in cured meats vary considerably depending on processing and storage methods, yet most surveys are conducted shortly after processing and therefore do not account for the reduction in residual nitrite that occurs during storage ${ }^{2}$. Longer storage times increase depletion but refrigeration inhibits the depletion process ${ }^{39}$. Also, residual nitrite analysis can be quite variable, even when restricted to a single method. Adding to the variability of estimates based on several surveys are differences in curing, preparation and testing methods; laboratories in which the surveys are conducted; and sources of meat samples. This high degree of variability is reflected in the low $r^{2}$ values shown in Fig. 1 and is illustrated for bacon in Fig. 2 , indicating that relatively little of the variation in residual nitrite $\left(\mathrm{mg} \mathrm{kg}^{-1}\right)$ is accounted for by publication year. Nevertheless, the significant coefficients from regressions of year on nitrite levels suggest that predicting nitrite exposure by year probably improves upon exposure estimates that ignore the timing of the exposure.

While we acknowledge that our estimates of nitrite levels in cured meats are not ideal, this is the first attempt, to our knowledge, to quantify potentially harmful levels of nitrite exposure and estimate corresponding cured meat consumption during pregnancy as it relates to paediatric brain tumour risk in offspring. Our conclusion is that a two- to three-fold increase in risk occurred at a relatively high level of nitrite exposure (e.g. corresponding to eating three hot dogs a day throughout pregnancy), but that much lower levels of exposure were also associated with moderately increased risk. Our observations could be improved upon by other studies that confirm the dose-response relationship we noted and by more scientifically valid estimates of residual nitrite levels in cured meats. Studies that include more subjects with relatively high exposure are necessary to increase the confidence in risk estimates for these exposure levels; however, that seems unlikely given the decline in nitrite levels that has occurred in cured meats over past decades.

\section{Acknowledgements}

This work was supported by NIH grant CA47082 from the National Cancer Institute and a grant from the Cancer Research Foundation of America. The authors thank Deirdre Terry and Kristina Paoff for their assistance in acquiring pertinent literature.

\section{References}

1 Lijinsky W, Epstein SS. Nitrosamines as environmental carcinogens. Nature 1970; 225: 21-3.
2 National Research Council. The Health Effects of Nitrate, Nitrite, and N-Nitroso Compounds. Washington, DC: National Academy Press, 1981.

3 Preston-Martin S, Pogoda JM, Mueller BA, Holly EA, Lijinsky W, Davis RL. Maternal consumption of cured meats and vitamins in relation to paediatric brain tumours. Cancer Epidemiol. Biomarkers Prev. 1996; 5: 599-605.

4 Ishida Y, Tamura M, Kanda H, Okamoto K. Histopathological studies of the nervous system tumours in rats induced by $N$ nitrosomethyl-urea. Acta Pathol. Jpn. 1975; 25: 385-401.

5 Koestner A, Derlinger RH, Wechsler W. Induction of neurogenic and lymphoid neoplasms by the feeding of threshold levels of methyl- and ethylnitrosourea precursors to adult rats. Food Cosmet. Toxicol. 1975; 13: 605-9.

6 Ivankovic S. Prenatal carcinogenesis. In: Nakahara W, Takayama S, Sugimura T, Odashima S, eds. Topics in Chemical Carcinogenesis. Tokyo: University of Tokyo Press, 1972: 463-72.

7 Rice J, Ward J. Age dependence of susceptibility to carcinogenesis in the nervous system. In: Selikoff I, Hammond E, eds. Brain Tumours in the Chemical Industry. New York: Annals of the New York Academy of Science, 1982: 274-89.

8 Buege DR, Lee MH, Cassens RG. Residual Nitrite Levels in Meat Products Manufactured by Wisconsin Meat Processors. Report No. A2983. Madison, WI: Research Division of the College of Agricultural and Life Sciences, University of Wisconsin, 1972 (available from Agricultural Bulletin Building, Madison, Wisconsin).

9 Greenberg RA. Nitrosopyrrolidine in United States cured meat products. In: Tinbergen BJ, Krol B, eds. Proceedings of the 2nd International Symposium on Nitrite in Meat Products, 7-10 September 1976. Zeist, the Netherlands: Center for Agricultural Publishing and Documentation, 1977 : 203-10.

10 Ceres Forum. Nitrite as a Food Additive: State of the Science. Washington, DC: Georgetown University Center for Food and Nutrition Policy, 1997.

11 Hartge P, Brinton LA, Rosenthal JF, Cahill JI, Hoover RN, Waksberg J. Random digit dialing in selecting a populationbased control group. Am. J. Epidemiol. 1984; 120: 825-33.

12 Howe GR, Harrison L, Jain M. A short diet history for assessing dietary exposure to $N$-nitrosamines in epidemiologic studies. Am. J. Epidemiol. 1986; 124: 595-602.

13 Panalaks T, Iyengar JR, Sen NP. Nitrate, nitrite, and dimethylnitrosamine in cured meat products. J. Assoc. Off. Anal. Chem. 1973; 56: 621-5.

14 Panalaks T, Iyengar JR, Donaldson BA, Miles WF, Sen NP. Further survey of cured meat products for volatile $\mathrm{N}$ nitrosamines. J. Assoc. Off. Anal. Chem. 1974; 57: 806-12.

15 Sen NP, Iyengar JR, Donaldson BA, Panalaks T. Effect of sodium nitrite concentration on the formation of nitrosopyrrolidine and dimethylnitrosamine in fried bacon. J. Agric. Food. Chem. 1974; 22: 540-1.

16 Sen NP, Donaldson B, Seaman S, Collins B, Iyengar JR. Recent nitrosamine analyses in cooked bacon. J. Inst. Can. Sci. Technol. Ailment. 1977; 10: A13-14.

17 Theiler RF, Aspelund TG, Sato K, Miller AF. Model system studies on $N$-nitrosamine formation in cured meats: the effect of slice thickness. J. Food Sci. 1981; 46: 691-3.

18 Pensabene JW, Feinberg JI, Dooley CJ, Phillips JG, Fiddler W. Effect of pork belly composition and nitrite level on nitrosamine formation in fried bacon. J. Agric. Food Chem. 1979; 27: 842-5.

19 Pensabene JW, Fiddler W, Miller AJ, Phillips JG. Effect of preprocessing procedures for green bellies on $N$-nitrosopyrrolidine formation in bacon. J. Agric. Food Chem. 1980; 28: 966-70.

20 Pensabene JW, Fiddler W. $N$-nitrosothiazolidine in cured meat products. J. Food Sci. 1983; 48: 1870-1. 
21 Pensabene JW, Fiddler W. Determination of volatile $N$ nitrosamines in frankfurters containing minced fish and surimi. J. Assoc. Off. Anal. Chem. 1988; 71: 839-43.

22 Pensabene JW, Fiddler W, Gates RA, Hale M, Jahncke M, Gooch J. $N$-nitrosothiazolidine and its 4-carboxylic acid in frankfurters containing Alaska pollock. J. Food Sci. 1991; 56 $1108-10$.

23 Fiddler W, Pensabene JW, Gates RA, Foster JM, Smith WJ Investigations on $N$-nitrosopyrrolidine in dry-cured bacon. $J$. Assoc. Off. Anal. Chem. 1989; 72: 19-22.

24 Wasserman AE, Fiddler W, Doerr RC, Osman SF, Dooley CJ. Dimethylnitrosamine in frankfurters. Food Cosmet. Toxic. 1972; 10: 681-4.

25 Nitrite Safety Council. A survey of nitrosamines in sausages and dry-cured meat products. Food Technol. 1980; 34: 4551, 53, 103.

26 Fiddler W, Doerr RC, Gates RA, Fox JB Jr. Comparison of chemiluminescent and AOAC methods for determining nitrite in commercial cured meat products. J. Assoc. Off. Anal. Chem. 1984; 67: 525-8.

27 Gates RA, Pensabene JW, Fiddler W. Comparison of three methods for determination of $N$-nitrosopyrrolidine in fried dry-cured bacon. J. Assoc. Off. Anal. Chem. 1984; 67: 236-9.

28 Binkerd EF, Kolari OE. The history and use of nitrate and nitrite in the curing of meat. Food Cosmet. Toxicol. 1975; 13 655-61.

29 Pensabene JW, Fiddler W, Gates RA, Fagan JC, Wasserman AE. Effect of frying and other cooking conditions on nitrosopyrrolidine formation in bacon. J. Food Sci. 1974; 39: $314-16$

30 Fiddler W, Feinberg JI, Pensabene JW, Williams AC, Dooley
CJ. Dimethylnitrosamine in souse and similar jellied curedmeat products. Food Cosmet. Toxicol. 1975; 13: 653-4.

31 United States Department of Agriculture, Food Safety and Quality Service. Study to Survey Nitrosamine Levels in Dry Cured Bacon, Hams, and Shoulders. Washington, DC: United States Department of Agriculture, 1980.

32 United States Department of Agriculture, Food Safety and Quality Service. Study of Nitrosamine Levels in Immersion Cured Bacon. Washington DC: United States Department of Agriculture, 1980.

33 Greenland S. Dose-response and trend analysis in epidemiology: alternatives to categorical analysis. Epidemiology 1995; 6: 356-65.

34 United States Department of Agriculture. Agricultural Research Service Nutrient Data Laboratory (Online). Available: http://www.nal.usda.gov/fnic/cgi-bin/nut_search.pl (2000, 15 Feb).

35 Preston-Martin S, Yu M, Benton B, Henderson BE. $N$-nitroso compounds and childhood brain tumours: a case-control study. Cancer Res. 1982; 42: 5240-5.

36 Kuijten RR, Bunin GR, Nass CC, Meadows AT. Gestational and familial risk factors for childhood astrocytoma: results of a case-control study. Cancer Res. 1990; 50: 2608-12.

37 Sarasua S, Savitz DA. Cured and broiled meat consumption in relation to childhood cancer: Denver, Colorado (United States). Cancer Causes Control 1994; 5: 141-8.

38 Bunin GR, Kuijten RR, Boesel CP, Buckley JD, Meadows AT. Maternal diet and risk of astrocytic glioma in children: a report from the Childrens Cancer Group (United States and Canada). Cancer Causes Control 1994; 5: 177-87.

39 Nordin HR. The depletion of added sodium nitrite in ham. Can. Inst. Food Sci. Technol. J. 1969; 2: 79-85. 